\title{
AVALIAÇÃO DA VELOCIDADE DE DESLOCAMENTO DE BARRAS FLUVIAIS DO RIO PARANÁ POR MEIO DE IMAGENS CBERS/CCD
}

\section{EVALUATION OF THE SPEED OF THE RIVER PARANA RIVER BAR THROUGH IMAGES CBERS/CCD}

\author{
Edvard Elias de Souza Filho \\ Departamento de Geografia, Universidade Estadual de Maringá - Avenida Colombo 5790, Zona 07 - CEP 87020-900 - \\ Maringá, PR - e-mail: souza.filho@pesquisador.cnpq.br \\ Bruno Tiago Condessoto Rigon \\ Programa de Pós-Graduação em Geografia, Universidade Estadual de Maringá - Avenida Colombo 5790, Zona 07 - \\ CEP 87020-900 - Maringá, PR - e-mail: brunotcr@hotmail.com
}

\begin{abstract}
Resumo
A formação do reservatório de Porto Primavera cortou o suprimento de sedimentos do rio Paraná. O primeiro efeito a ser observado foi a redução da carga suspensa e a seguir a progressiva retirada das formas de leito do rio. As barras fluviais são as formas ativas que menos foram afetadas, mas todas elas deslocam-se para jusante e a avaliação de sua velocidade de deslocamento é um parâmetro que deve ser conhecido para uma adequada avaliação das transformações que o canal está sofrendo. Portanto, o objetivo deste trabalho é avaliar a velocidade de deslocamento de quatro barras fluviais situadas entre a ilha Óleo Cru (SP) e a ilha Floresta (MS). Foram utilizadas imagens orbitais (CBERS 2 CCD) obtidas no período entre 2004 e 2007, a uma razão de três imagens por ano. Por meio do programa SPRING, as imagens foram georreferenciadas, a área do canal foi recortada. A partir das informações da banda $2(0,45-0,52 \mu \mathrm{m})$ a posição de cada barra foi definida e incorporada ao banco de dados. A comparação entre a posição da parte jusante de cada barra em cada data permitiu a avaliação do deslocamento ocorrido em cada intervalo de tempo. Os resultados permitiram observar que a velocidade média de deslocamento das quatro barras foi de $25,5 \mathrm{~m} / \mathrm{mês}$, com uma variabilidade temporal considerável, já que os valores médios ficaram situados entre $11 \mathrm{e} 43 \mathrm{~m} / \mathrm{mês}$. A velocidade de deslocamento das barras não foi afetada pela cominuição a que estão submetidas tampouco pelo gradiente do leito, mas em duas delas foi obtida correlação positiva com a descarga máxima, enquanto que em outras duas a correlação foi negativa. Os resultados permitem concluir que a movimentação das barras é controlada por fatores hidrodinâmicos locais.
\end{abstract}

Palavras-chave: barras fluviais, velocidade de deslocamento, rio Paraná

\begin{abstract}
The Porto Primavera Dam cutoff the sediment supply of the Parana River and the bed forms are moving downstream without replacement. The fluvial bars move more slowly than the bed forms and its displacement velocity is an important parameter to evaluate the channel change. The objective of this paper is evaluate the displacement velocity of the four fluvial bars located on the downstream reach of Porto Primavera Dam using temporal analysis of the orbital images. To do this, CBERS/CCD images obtained between 2004 and 2007 were used. The images were registered, the channel area was selected, and the fluvial bars are mapped and included in a georreferenciated data base. The difference of the position of the fluvial bars after a year
\end{abstract}


was evaluated and your displacement velocity was measured. The mean displacement velocity obtained was $25 \mathrm{~m} / \mathrm{month}$, the smallest value was $11 \mathrm{~m} /$ month and the maximum was $43 \mathrm{~m} / \mathrm{month}$. The armoring of the bars and the fluvial bed gradient does not control the velocity and the velocity of two bars was related with the major fluvial discharge. The velocity of other bars was inversely proportional to the major fluvial discharge. The results obtained shows that the fluvial bars displacement velocity are controlled by local hydrodynamic.

Keywords: fluvial bars, displacement velocity, Paraná River.

\section{Introdução}

A formação do reservatório da UHE Engenheiro Sérgio Motta (Porto Primavera) promoveu diversas modificações na dinâmica fluvial do rio Paraná, conforme relatam Souza Filho (1999) e Souza Filho et al. (2004). Entre os efeitos destacam-se o controle de descargas (SILVA, 2007; SOUZA FILHO, 2009) e o corte do suprimento detrítico (ROCHA e SOUZA FILHO, 2008). O controle de descargas foi responsável pela diminuição da frequência das descargas extremas e o corte de suprimentos detríticos teve por consequência a diminuição da carga suspensa a valores irrisórios, a progressiva remoção dos sedimentos de fundo e das formas de leito.

Após o fechamento da barragem, o rio iniciou um processo de ajuste que vem se propagando de montante para jusante e tal processo desenvolve-se em diferentes velocidades, conforme relatado por Souza Filho e Stevaux (2008). De acordo com os autores mencionados, a redução da carga suspensa foi a variável que teve modificação mais rápida enquanto o deslocamento das barras fluviais foi aquela que teve alteração mais lenta.

O rio Paraná tem seu leito dominado por ondas de areia e dunas sub-aquosas de grande porte e por barras transversais que podem atingir mais de 60 hectares (SOUZA FILHO, 1993). Tais formas movimentam-se diagonalmente ao canal e distribuem as linhas de maior velocidade de fluxo. A movimentação das formas de leito e das barras faz com que o talvegue seja móvel, uma vez que as linhas de maior velocidade de fluxo também são reposicionadas.

Uma vez que as barras fluviais migram para jusante e a barragem de Porto Primavera não permite o fluxo de sedimentos de fundo, a porção do canal situada nas proximidades da barragem tende a ser completamente desprovida de quaisquer formas de leito. Assim, o conhecimento da velocidade de deslocamento dessas formas permite estabelecer o tempo máximo do processo de ajuste a que o canal está submetido.

A avaliação da velocidade de deslocamento de uma barra fluvial exige a identificação de sua posição em diferentes datas, de forma que seja possível verificar qual foi o seu deslocamento em um determinado intervalo de tempo. No caso de não haver dados de campo, os produtos de sensores remotos podem ser utilizados para tal finalidade, desde que sua resolução espacial seja considerada. A disponibilidade das imagens CCD do satélite CBERS-2 tornam essa tarefa possível, visto que sua resolução permite a avaliação de deslocamentos superiores a 20 metros.

Por essas razões, o objetivo desse trabalho é utilizar imagens CCD/CBERS para avaliar a velocidade de deslocamento de quatro barras fluviais situadas à jusante da barragem de Porto Primavera, no segmento fluvial compreendido entre a ilha Óleo Cru (SP) e a Ilha Floresta (MS), no período compreendido entre 2004 e 2007.

\section{A Área de Estudo}

O segmento onde as quatro barras fluviais estão localizadas possui cerca de cinquenta quilômetros de comprimento, contados a partir da barragem de Porto Primavera. O rio alterna intervalos onde exibe canais múltiplos, separados por grandes ilhas fluviais e segmentos de canal simples (Figura 1), podendo ser caracterizado como multicanal. Antes do fechamento da barragem o fluxo de água no canal era dividido por formas de leito e por barras fluviais, mas a cominuição e a remoção das formas de leito vêm tornando o talvegue fixo (SOUZA FILHO \& STEVAUX, 2008).

O gradiente do leito foi avaliado no início da década de 1990 e à época mostrava valores diferentes ao longo do perfil longitudinal. No intervalo entre a barragem de Porto Primavera e pouco acima da foz do rio Paranapanema, o gradiente era de $6,9 \mathrm{~cm} / \mathrm{km}$, entre este último local e o distrito de Porto São José era de $20 \mathrm{~cm} / \mathrm{km}$, por fim, no segmento final o valor era de $3,1 \mathrm{~cm} / \mathrm{km}$ (SOUZA FILHO, 1993). O gradiente do último intervalo citado foi confirmado por meio de levantamento batímétrico efetuado entre 1994 e 1995 (MARTONNI \& LESSA, 1999) e a variação de gradiente de montante para jusante foi confirmada por ROCHA (2002).

As barras fluviais possuem forma em tricúspide, com duas extremidades voltadas para jusante. Em corte transversal elas são simétricas, mas em corte longitudinal elas possuem uma forte assimetria, marcada por baixo gradiente na porção voltada para montante e forte inclinação na parte voltada para jusante. Tal assimetria é também encontrada nas formas de leito ainda existentes no rio Paraná, seja nas ondas de areia ("macro sandwaves"), ou nas dunas sub-aquosas. 


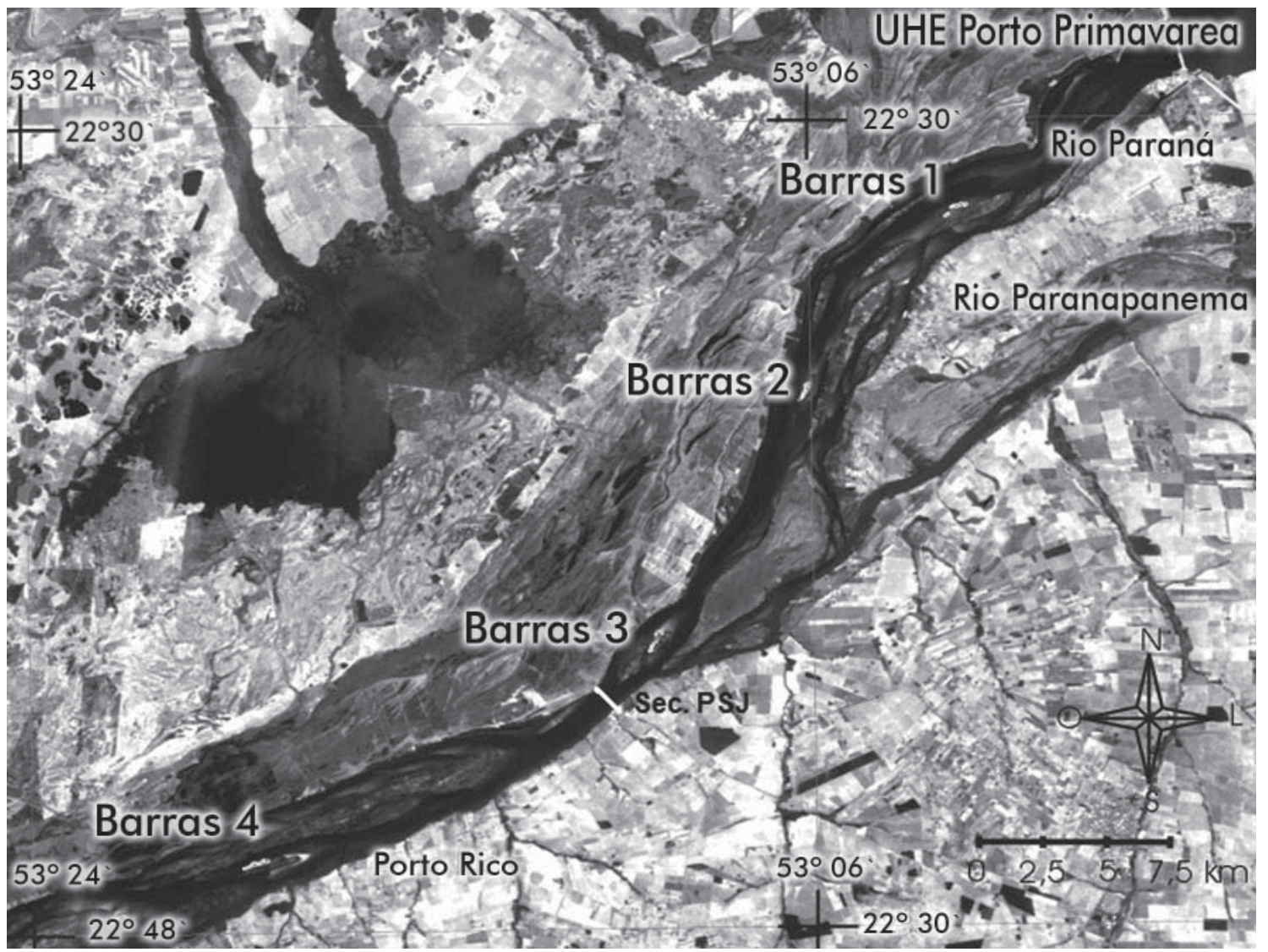

Figura 1 - Localização das barras estudadas e da seção de Porto São José (Sec.PSJ). Imagem CBERS 2B / CCD, recorte da cena.

As formas de leito na seção de Porto São José (Figura 1) deslocavam-se a uma velocidade média próxima a 70m/mês (STEVAUX e TAKEDA, 2002; CRISPIM, 2001) antes do fechamento da barragem e tiveram sua velocidade diminuída após 1998 (MARTINS, ; STEVAUX, 2007), conforme Tabela 1. A movimentação das barras fluviais é feita principalmente pelo deslocamento das formas de leito de pequeno e médio porte situadas em sua parte superior e média, mas as grandes formas situadas em sua porção basal movimentam-se apenas durante as grandes cheias. Por essa razão, considerou-se que sua velocidade de deslocamento fosse inferior à das formas de leito.

Tabela 1 - Velocidade de deslocamento das formas de leito em Porto São José, de acordo com os referidos autores.

\begin{tabular}{|c|c|c|c|c|c|}
\hline & $\begin{array}{l}\text { STEVAUX } \\
\text { TAKFDA, 2002 }\end{array}$ & $\begin{array}{l}\text { CRISPIM, } \\
2001\end{array}$ & $\begin{array}{l}\text { MARTINS, } \\
2004\end{array}$ & \multicolumn{2}{|c|}{ STEVAUX 2007 } \\
\hline & $1994-95$ & 2000 & $12 / 2003$ & $07 / 2005$ & $05 / 2006$ \\
\hline $\begin{array}{c}\text { Velocidade média } \\
\text { (m/mês) }\end{array}$ & 67 & 62 & 48 & 43,2 & 51,2 \\
\hline
\end{tabular}

A descarga fluvial deste segmento é monitorada por meio de uma estação fluviométrica (Estação de Porto São José, registro 64575003 - ANA) ativa desde 01/10/1963. A série histórica demonstra que a descarga média no período entre 1963 a 2007 foi de $8.800 \mathrm{~m}^{3} / \mathrm{s}$, tendo atingido o valor mínimo de $2.551 \mathrm{~m}^{3} / \mathrm{s}$ em 22 e 29 de setembro de 1969 (cota de $0,27 \mathrm{~m}$ ) e o valor máximo de $33.740 \mathrm{~m}^{3} / \mathrm{s}$ em 18/02/1983 (cota de $8,74 \mathrm{~m}$ ).

Contudo, a instalação de barragens ao longo do rio Paraná e de seus afluentes promoveu um progressivo controle da descarga, sendo possível distinguir o Período Natural (anterior a 1971, inclusive) e o Período Alterado (posterior a 1972, inclusive). O último período pode ser subdividido em Período Transicional (1972 a 1981), Período Regulado pelo Efeito Cascata dos Reservatórios (1982 a 1998) e Período Regulado pela UHE Porto Primavera (a partir de 1999), de acordo com Rocha (2002). Os diversos períodos podem ser distinguidos pelos diferentes valores de descarga média ( $\mathrm{Fi}$ gura 2) e tais dados demonstram que ocorreu um aumento da vazão fluvial até o final da década de 1990, quando os valores voltaram a declinar (SOUZA FILHO, 2009). 


\section{Cota média e descarga média nos diferentes períodos}

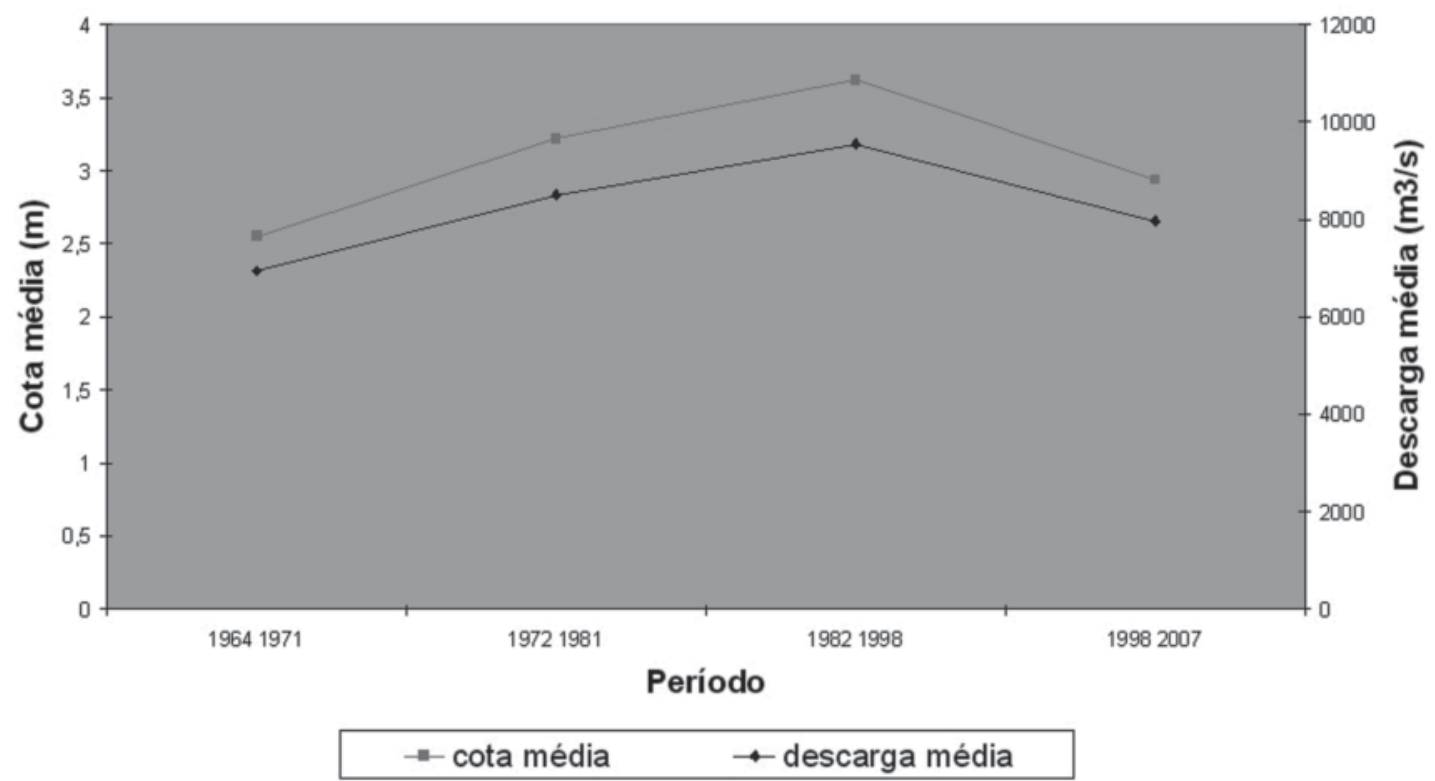

Figura 2 - Variação temporal da cota fluviométrica média dos quatro diferentes períodos. (Souza Filho, 2009).

A redução dos valores de descarga média pode estar ou não relacionado à construção da barragem (OKAWA, 2008), mas um dos efeitos provocados por ela é a redução dos valores de descarga extremos (SOUZA FILHO, 1999, 2009). Assim, há dois fatores que podem influenciar a movimentação das barras fluviais: as modificações do regime de descarga e o corte de suprimentos detríticos.

\section{Metodologia}

A escolha de imagens CCD/CBERS para o desenvolvimento do trabalho deveu-se à sua gratuidade, resolução temporal e à resolução espacial de 20 metros. Quando da realização do estudo, apenas as imagens do satélite CBERS-2 e dos satélites LANDSAT estavam disponíveis de forma gratuita, mas a resolução dos produtos MSS não é adequada para a o trabalho e a resolução dos produtos TM é de 30 metros. A escolha das imagens CCD limitou o período de análise ao intervalo entre 2004 e 2007, face à data inicial de funcionamento do satélite.

A hipótese de trabalho que deu origem a este estudo é que a velocidade de deslocamento das formas de leito depende da velocidade de fluxo a que elas estão submetidas. Em canais livres, a velocidade de fluxo é diretamente proporcional à descarga fluvial, portanto, a velocidade de deslocamento das barras deve ser proporcional à descarga fluvial. Por outro lado, sob mesma descarga fluvial, a velocidade de fluxo varia conforme o gradiente do leito, dessa maneira espera-se que os segmentos com maior gradiente tenham maior velocidade de fluxo. No caso do intervalo entre Porto São José e o Porto 18, tal afirmação foi comprovada por Martonni \& Lessa (1999).

Contudo, o corte do suprimento detrítico faz com que as formas de leito percam sua fração mais fina e sofram cominuição (SOUZA FILHO \& STEVAUX, 2008). Nesse caso há a possibilidade de que a velocidade de deslocamento diminua ao longo do tempo e a proporção entre descarga fluvial e a velocidade de deslocamento seja modificada. Essa possibilidade teve de ser testada antes do desenvolvimento do trabalho. Para isso, foi elaborada uma análise de regressão entre os dados de velocidade de deslocamento das formas de leito e a descarga fluvial média e máxima do período em que as medidas foram feitas, por meio do uso do "software" "Statistica 7".

Uma vez que o deslocamento das barras fluviais é mais complexo do que o das formas de leito, foram escolhidas quatro barras situadas a diferentes distancias da barragem de Porto Primavera. Tal escolha foi baseada na hipótese de que o ajuste fluvial ocorre de montante para jusante e a alteração do leito móvel atingiria as barras em tempos diferentes.

O passo seguinte foi a seleção das quatro barras fluviais. A escolha das barras a serem monitoradas foi realizada com base em dois critérios: seu porte e sua persistência ao longo do período analisado. A escolha de barras de grandes proporções deveu-se à maior facilidade de visualização em imagens orbitais, enquanto que a escolha de barras que se mantiveram emersas ao longo do período deveu-se à necessidade da comparação das variações de velocidade entre todas as formas ao longo do período estudado. 
O intervalo de tempo a ser utilizado entre as passagens dependeu de duas variáveis: a existência de imagens sem cobertura de nuvens e o tempo mínimo necessário para que a resolução espacial do produto permitisse a avaliação do deslocamento com menor margem de erro.

O intervalo de tempo mínimo entre as passagens poderia ser estimado por meio do uso dos menores valores observados para o deslocamento das formas de leito, no caso, entre 40 e 50 metros por mês (Tabela 1), mas foi realizada uma verificação preliminar com dados de campo e fotografias aéreas, uma vez que as barras poderiam ter velocidade de deslocamento menor do que a das formas de leito.

Considerando a estimativa preliminar da velocidade de deslocamento das barras e a resolução espacial das imagens a serem utilizadas, foi realizada a escolha das imagens de forma a permitir verificar o deslocamento em intervalos próximos a um ano. O intervalo de tempo escolhido permitiu a minimização da margem de erro do posicionamento das barras e cobre o intervalo de vazante cheia vazante. Dessa forma foram selecionadas as imagens CCD da órbita 161, ponto 125 do satélite CBERS-2 com passagem em: 24/03/04, 09/06/05, 04/07/06 e 07/06/07.

A disponibilidade de imagens sem cobertura de nuvens possibilitou a escolha de outros dois conjuntos de 4 imagens, que foram utilizados para aumentar a confiabilidade da avaliação das velocidades de deslocamento das barras. As datas escolhidas para o segundo conjunto foram: 22/09/04, 26/08/05, 25/08/06 e 19/09/07. As datas do terceiro conjunto foram: 13/11/04, 12/11/05, 11/11/06 e 29/10/07, sendo que a imagem da última passagem foi obtida pelo satélite CBERS-2B.

As imagens foram baixadas a partir de solicitação feita ao INPE (www.dgi.inpe.br/CDSR) e registradas com base na imagem 223/076 do LANDSAT 7/ ETM de 12/05/2000, obtida no "site" do USGS, já georreferenciada e adequada ao sistema de projeção UTM e datun WGS84. O registro das imagens foi feito por meio do uso do "software" SPRING 4.3, assim como os demais procedimentos realizados com as imagens.

As imagens georreferenciadas foram verificadas para observar a existência de deslocamento originário de erro de registro e a área de estudo foi recortada. $\mathrm{O}$ trabalho utilizou as imagens da banda $2(0,45-0,52 \mu \mathrm{m}$ - azul), que permite visualizar parte da porção submersa das barras e definir com maior acuidade sua parte jusante, utilizada como referência para as medidas, já que possui alta inclinação. As diferenças de posição foram medidas comparando-se as imagens de acordo com as sequências de datas já mencionadas.

A velocidade de deslocamento foi obtida por meio da divisão da distancia percorrida por cada barra pelo tempo transcorrido entre a obtenção das imagens. Os dados obtidos foram correlacionados à descarga média e máxima em cada intervalo de tempo por meio do uso do "software" "Statistica 7".

\section{Resultados e Discussão}

Os dados existentes a respeito da velocidade de deslocamento das formas de leito mostram redução de valores ao longo do tempo, conforme indicado na Tabela 1. Contudo, quando os dados são analisados em conjunto com os respectivos valores de descarga média e a descarga máxima, observa-se que a redução ou aumento da velocidade de deslocamento das formas coincide com a diminuição ou aumento dos valores de descarga (Tabela 2).

\section{Tabela 2 - Velocidade de deslocamento das formas de leito em Porto São José e valores de descarga média e máxima no período.}

\begin{tabular}{|c|c|c|c|c|c|}
\hline & $1994-95$ & 2000 & $12 / 2003$ & $07 / 2005$ & $05 / 2006$ \\
\hline Velocidade média (m/més) & 67 & 62 & 48 & 43,2 & 51,2 \\
\hline Descarga Média $\left(\mathrm{m}^{3} / \mathrm{s}\right)$ & 8.983 & 7.903 & 7.196 & 6.695 & 7.748 \\
\hline Descarga Máxima $\left(\mathrm{m}^{3} / \mathrm{s}\right)$ & 19.037 & 13.993 & 9.096 & 7.444 & 8.825 \\
\hline
\end{tabular}

A análise de regressão obtida entre os dados de velocidade de deslocamento e a descarga fluvial encontra-se na Figura 3 , assim como os valores de $\mathrm{r}^{2}$. Os valores obtidos para $\mathrm{r}^{2}$ são elevados, indicando a existência de forte correlação entre a descarga fluvial e a velocidade de deslocamento das barras. O maior valor de $\mathrm{r}^{2}$ apresentado pela regressão entre a velocidade de deslocamento das barras e a velocidade máxima observada reforça ainda mais a afirmação anterior.
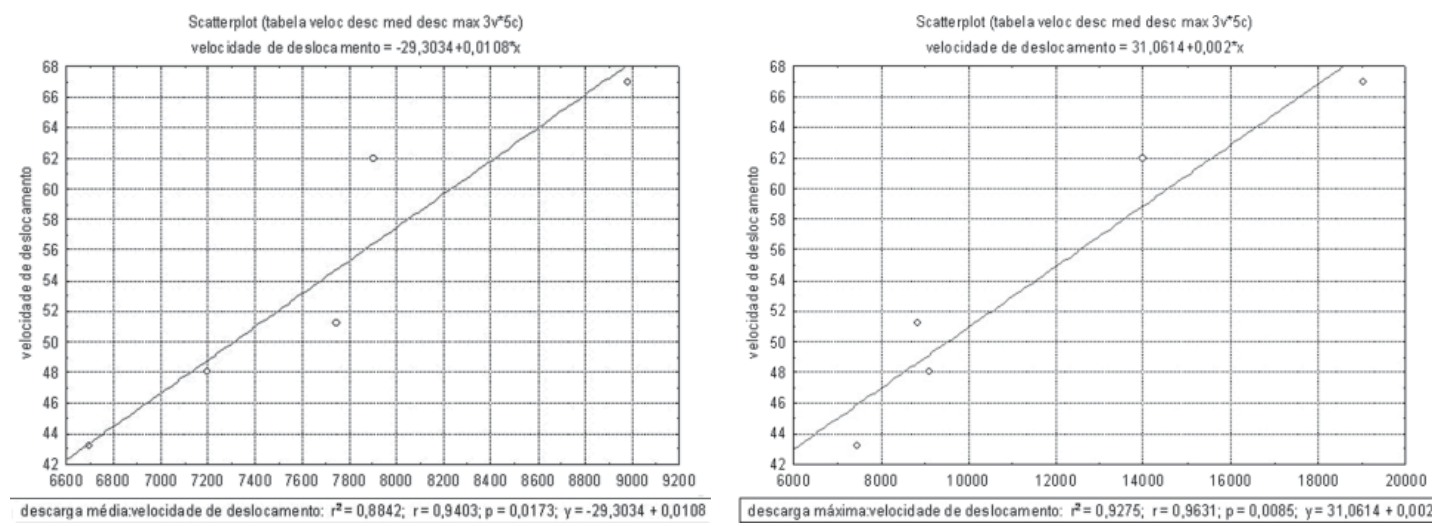

Figura 3 - Resultado da análise de regressão entre a velocidade de deslocamento das formas de leito do rio Paraná na seção de Porto São José e a descarga média (acima) e máxima (abaixo). 
A estimativa preliminar da velocidade de deslocamento das barras utilizou a mudança de posição da barra 4 (Figura 1) observada no intervalo de um ano. A fotografia aérea obtida pela COPEL em setembro de 1996 (Figura 4) mostra que a parte jusante da barra encontrava-se a 300 metros da parte montante da ilha. Em setembro de 1997 essa distância não mais existia, conforme foi observado em trabalho de campo. Tais dados permitiram avaliar que a velocidade de deslocamento da barra 4 foi de 25 metros por mês durante aquele período de tempo.

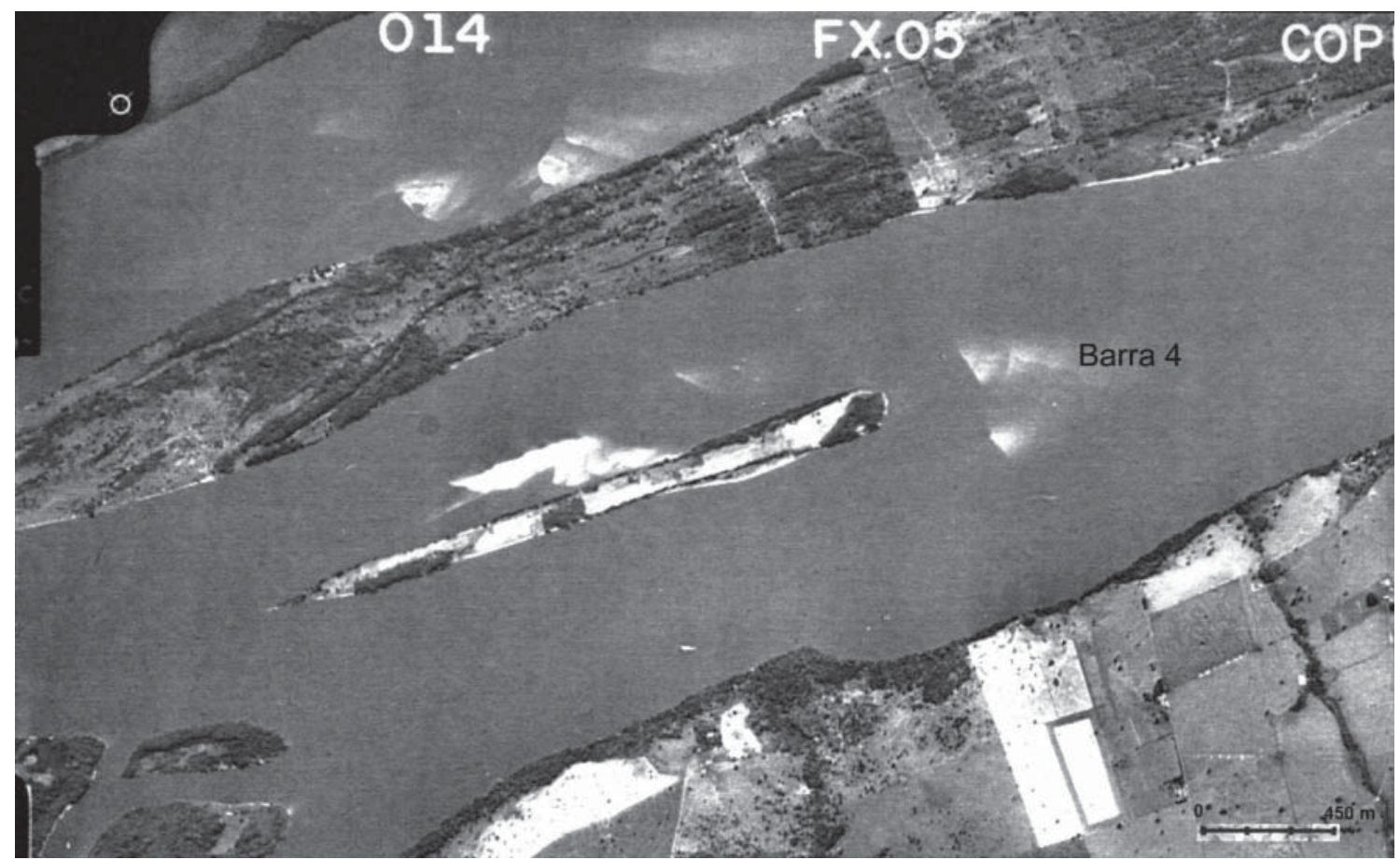

Figura 4 - Fotografia aérea de parte do canal do rio Paraná, com ilhas e barras fluviais. Em destaque a posição da barra 4 em setembro de 1996.

Tal informação, além de confirmar que a velocidade de deslocamento das barras é inferior à velocidade das formas de leito, permitiu validar o intervalo de tempo mínimo utilizado (11,1 meses). Ou seja, um produto com resolução espacial de 20 metros pode ser utilizado para avaliar uma distâcia de pouco mais de 250 metros, embora a margem de erro possa ser grande.

Os valores de deslocamento obtidos variaram entre $132 \mathrm{~m}$ e $520 \mathrm{~m}$ (Tabela 3), indicando que a margem de erro das medidas ficou compreendida entre 8 e $30 \%$, considerando uma precisão de 40 metros ( 2 vezes a resolução linear das imagens).

Tabela 3 - Deslocamento de cada barra fluvial em cada intervalo de tempo utilizado.

\begin{tabular}{|l|r|c|c|c|c|}
\hline & & Barra 1 & Barra 2 & Barra 3 & Barra 4 \\
\hline Intervalo de tempo & Meses & Distância (m) & Distância (m) & Distância (m) & Distáncia (m) \\
\hline $24 / 03 / 04$ a 09/06/05 & 14,5 & 362 & 354 & 310 & 448 \\
\hline $09 / 06 / 05$ a 04/07/06 & 12,8 & 316 & 356 & 199 & 460 \\
\hline $04 / 07 / 06$ a 07/06/07 & 11,1 & 354 & 240 & 218 & 310 \\
\hline & & & & & \\
\hline $22 / 09 / 04$ a 26/08/05 & 11,1 & 342 & 352 & 311 & 446 \\
\hline 26/08/05 a 25/08/06 & 12,0 & 269 & 284 & 167 & 420 \\
\hline $25 / 08 / 06$ a 19/09/07 & 12,8 & 388 & 243 & 238 & 260 \\
\hline & & & & & \\
\hline $13 / 11 / 04$ a 12/11/05 & 12,0 & 381 & 381 & 341 & 520 \\
\hline $12 / 11 / 05$ a 11/11/06 & 12,0 & 269 & 249 & 132 & 337 \\
\hline $11 / 11 / 06$ a 29/10/07 & 11,6 & 303 & 206 & 196 & 220 \\
\hline
\end{tabular}

Os dados permitiram verificar que a velocidade média de deslocamento de todas as barras no período entre março de 2004 e outubro de 2007 foi de 25,5 metros por mês, com valor máximo de $43,3 \mathrm{~m} /$ mês (barra 4 no período entre novembro de 2004 a novembro de 2005) e valor mínimo de $11 \mathrm{~m} / \mathrm{mês}$ (barra 3, no período entre novembro de 2005 e novembro de 2006). No período completo, a barra 4 deslocou -se mais rapidamente (31,4 m/mês), seguida pela barra $1(27,3 \mathrm{~m} / \mathrm{mês})$ e pela barra $2(24,3 \mathrm{~m} / \mathrm{mês})$, enquanto a barra 3 foi a que teve deslocamento mais lento (19,3 m/mês), conforme Tabela 4 .

Tabela 4 - Velocidade de deslocamento das barras fluviais em cada intervalo de tempo utilizado.

\begin{tabular}{|c|c|c|c|c|c|}
\hline & Barra 1 & Barra 2 & Barra 3 & Barra 4 & \\
\hline Intervalo de tempo & $\begin{array}{l}\text { Velocidade } \\
\text { (m/mês) }\end{array}$ & $\begin{array}{l}\text { Velocidade } \\
\text { (m/més) }\end{array}$ & $\begin{array}{l}\text { Velocidade } \\
\text { (m/més) }\end{array}$ & $\begin{array}{l}\text { Velocidade } \\
\text { (m/més) }\end{array}$ & $\begin{array}{l}\text { Média } \\
\text { (m/més) }\end{array}$ \\
\hline $24 / 03 / 04$ a 09/06/05 & 25,0 & 24,4 & 21,4 & 30,9 & 25,4 \\
\hline 09/06/05 a 04/07/06 & 24,7 & 27,8 & 15,6 & 36,0 & 26,0 \\
\hline $04 / 07 / 06$ a $07 / 06 / 07$ & 31,9 & 21,6 & 19,6 & 27,9 & 25,3 \\
\hline média & 27,2 & 24,6 & 18,9 & 31,6 & 25,6 \\
\hline $22 / 09 / 04$ a $26 / 08 / 05$ & 30,8 & 31,7 & 28,0 & 40,2 & 32,7 \\
\hline $26 / 08 / 05$ a $25 / 08 / 06$ & 22,4 & 23,7 & 13,9 & 35,0 & 23,8 \\
\hline $25 / 08 / 06$ a $19 / 09 / 07$ & 30,3 & 19,0 & 18,6 & 20,3 & 22,1 \\
\hline média & 27,8 & 24,8 & 20,2 & 31,8 & 26,2 \\
\hline $13 / 11 / 04$ a $12 / 11 / 05$ & 31,8 & 31,8 & 28,4 & 43,3 & 33,8 \\
\hline $12 / 11 / 05$ a $11 / 11 / 06$ & 22,4 & 20,8 & 11,0 & 28,1 & 20,6 \\
\hline $11 / 11 / 06$ a $29 / 10 / 07$ & 26,1 & 17,8 & 16,9 & 19,0 & 20,0 \\
\hline média & 26,8 & 23,5 & 18,8 & 30,1 & 24,8 \\
\hline Média final & 27,3 & 24,3 & 19,3 & 31,2 & 25,5 \\
\hline
\end{tabular}


Tais valores indicam que a velocidade de deslocamento das barras não está sendo controlada pela cominuição dessas formas, uma vez que a barra 1 deslocou-se mais rapidamente que as barras 2 e 3 . Caso o processo de cominuição estivesse influenciando o movimento das barras, as velocidades deveriam ser crescentes no sentido de montante para jusante, pois a cominuição estaria mais avançada na barra 1 e seria menos intensa na barra 4.

A mesma afirmação pode ser feita com relação ao gradiente do leito, uma vez que a barra mais veloz encontra-se no segmento com menor declividade. Contudo, uma vez que os dados referentes a esta variável são antigos e são valores médios, é possível que as modificações locais da inclinação do leito possam controlar o deslocamento das barras.

A variação das velocidades de deslocamento ao longo do tempo mostra que a barra 4 movimentou-se mais rapidamente que as demais no período entre 2004 e 2006, mas no período entre 2006 e 2007, a barra 1 foi mais veloz (Tabela 4). A comparação entre as velocidades de deslocamento das barras e os valores de descarga média e máxima nos respectivos intervalos de tempo (Tabela 5) não demonstrou relação clara entre estas variáveis em uma análise preliminar, mas a análise de regressão obteve alguns resultados.

\section{Tabela 5 - Descarga média e máxima registrada na Estação de Porto São José nos intervalos de tempo utilizados.}

\begin{tabular}{|c|c|c|}
\hline Intervalo de tempo & Descarga média $\left(\mathrm{m}^{2} / \mathrm{s}\right)$ & Descarga máxima $\left(\mathrm{m}^{3 / 8}\right)$ \\
\hline $24 / 03 / 04$ a $09 / 06 / 05$ & 8233 & 20030 \\
\hline $09 / 06 / 05$ a 04/07/06 & 8280 & 14288 \\
\hline $04 / 07 / 06$ a 07/06/07 & 9600 & 18800 \\
\hline $22 / 09 / 04$ a 26/08/05 & 8373 & 20030 \\
\hline $26 / 08 / 05$ a 25/08/06 & 8546 & 14288 \\
\hline $25 / 08 / 06$ a $19 / 09 / 07$ & 9238 & 18800 \\
\hline $13 / 11 / 04$ a 12/11/05 & 8169 & 20030 \\
\hline $12 / 11 / 05$ a $11 / 11 / 06$ & 8772 & 14288 \\
\hline $11 / 11 / 06$ a 29/10/07 & 9407 & 18800 \\
\hline
\end{tabular}

A velocidade de deslocamento da barra 1 mostrou boa correlação com a descarga média apenas no período entre 24/03/04 a 07/06/07 (Tabela 6), mas apresentou uma boa correlação com a descarga máxima nos demais intervalos de tempo (Tabela 7). A velocidade de deslocamento da barra 2 apresentou correlação negativa com a descarga média e não mostrou relação com a descarga máxima, exceto no período entre 24/03/04 a 07/06/07. A velocidade de deslocamento da barra 3 não apresentou correlação com a descarga média, mas mostrou correlação direta com a velocidade máxima. Por fim, a velocidade de deslocamento da barra 4 mostrou uma relação negativa com a velocidade média, mas não apresentou relação com a velocidade máxima, com exceção do período entre 24/03/04 a 07/06/07.
Tabela 6 - Resultado da análise de regressão linear entre a velocidade de deslocamento das barras e a descarga média em cada período.

\begin{tabular}{|c|c|c|c|c|c|c|c|c|}
\hline \multirow[t]{2}{*}{ Periodo } & \multicolumn{2}{|l|}{ Barra 1} & \multicolumn{2}{|l|}{ Barra 2} & \multicolumn{2}{|l|}{ Barra 3} & \multicolumn{2}{|l|}{ Barra 4} \\
\hline & $r^{2}$ & relaçấo & $r^{2}$ & relaçăo & $r^{2}$ & relaçẵo & $\mathrm{r}^{2}$ & relaçẵo \\
\hline $\begin{array}{c}24 / 03 / 04 \text { a } \\
07 / 06 / 07\end{array}$ & 0,9955 & positiva & 0,6721 & negativa & 0,0339 & năo há & 0,5826 & negativa \\
\hline $\begin{array}{c}22 / 09 / 04 \mathrm{a} \\
19 / 09 / 07\end{array}$ & 0,0766 & não há & 0,7848 & negativa & 0,1378 & não há & 0,9958 & negativa \\
\hline $\begin{array}{c}13 / 11 / 04 \text { a } \\
29 / 10 / 07\end{array}$ & 0,3480 & não há & 0,8928 & negativa & 0,4075 & nå̀ hả & 0,9750 & negativa \\
\hline $\begin{array}{c}24 / 03 / 04 \text { a } \\
29 / 10 / 07\end{array}$ & 0,0005 & nào há & 0,5212 & negativa & 0,1152 & nào há & 0,6149 & negativa \\
\hline
\end{tabular}

Tabela 7 - Resultado da análise de regressão linear entre a velocidade de deslocamento das barras e a descarga máxima em cada período.

\begin{tabular}{|c|c|c|c|c|c|c|c|c|}
\hline Período & \multicolumn{2}{|l|}{ Barra 1} & \multicolumn{2}{|l|}{ Barra 2} & \multicolumn{2}{|l|}{ Barra 3} & \multicolumn{2}{|l|}{ Barra 4} \\
\hline & $r^{2}$ & relaçào & $\mathrm{r}^{2}$ & relação & $r^{2}$ & relação & $\mathrm{r}^{2}$ & relaçáo \\
\hline $\begin{array}{c}24 / 03 / 04 a \\
07 / 06 / 07\end{array}$ & 0,1212 & nào bá & 0,6118 & negativa & 0,9894 & positiva & 0,6998 & positiva \\
\hline $\begin{array}{c}22 / 09 / 04 a \\
19 / 09 / 07\end{array}$ & 0,9771 & positiva & 0,1200 & naิo há & 0,7626 & positiva & 0,0041 & năo há \\
\hline $\begin{array}{c}13 / 11 / 04 \text { a } \\
29 / 10 / 07\end{array}$ & 0,8178 & positiva & 0,2499 & năo há & 0,7681 & positiva & 0,1168 & nằo há \\
\hline $\begin{array}{c}24 / 03 / 04 \text { a } \\
29 / 10 / 07\end{array}$ & 0,5409 & positiva & 0,0009 & naิo há & 0,6815 & positiva & 0,0010 & não há \\
\hline
\end{tabular}

Tais dados indicam que as barras 1 e 3 têm sua velocidade de deslocamento controlada pela descarga máxima, mas não pela descarga média, ou seja, há um limiar de descarga fluvial e de velocidade de fluxo a partir do qual as barras passam a se movimentar de forma similar às formas de leito.

As barras 2 e 4 movimentam-se mais vagarosamente conforme aumenta a descarga média e elas não são controladas pela descarga máxima, a não ser quando seu valor é muito alto. Nessa situação elas movimentam-se mais lentamente. A relação inversa entre as variáveis pode indicar que as barras estejam situadas em locais de acumulação de sedimentos.

Os resultados obtidos demonstram que a velocidade de deslocamento das barras é controlada por fatores locais. Nesse caso o controle pode ser feito pelo gradiente local do leito e/ou pelas condições hidrodinâmicas proporcionadas pelas próprias formas.

\section{Conclusão}

A técnica utilizada para avaliar a velocidade de deslocamento das barras fluviais mostrou resultados satisfatórios e compatíveis com os valores obtidos em campo. Contudo, uma vez que é pioneira, é necessário que sejam realizadas outras aferições para comprovar sua aplicabilidade. Tais aferições podem ser realizadas a partir de dados de campo ou por meio do uso de imagens de alta resolução.

Os dados obtidos demonstraram que a cominuição e o gradiente médio dos segmentos fluviais não controlam a velocidade de deslocamento das barras e que a descarga fluvial 
possui um controle complexo sobre a variável. Conforme o local, os altos valores de descarga podem fazer com que a barra se desloque como uma forma de leito ou pode fazer com que a barra se movimente mais lentamente, favorecendo seu crescimento.

\section{Referências Bibliográficas}

CRISPIM J.Q. Alterações na hidrologia do canal após construção de reservatório à montante: o caso da Usina Hidrelétrica de Porto Primavera, Rio Paraná. Dissertação de Mestrado, Universidade Estadual de Maringá, Pós-graduação em Ecologia de Ambientes Aquáticos Continentais, Maringá. 25 p., 2001.

MARTINS, D.P. Caracterização e Dinâmica das Formas de Leito do Rio Paraná: Proposição de Gerenciamento e Conservação. Dissertação de Mestrado Universidade Estadual de Maringá, Programa de Pós-Graduação em Geografia, Maringá. 63 p., 2004.

MARTONI, A.M. \& LESSA R.C. Modelagem hidrodinâmica do canal do rio Paraná, trecho Porto São José - Porto 18. Parte II: Calibragem do modelo. Acta Scientiarum, Maringá, v.21, n. 4, p. 961-970, 1999.

OKAWA, C.M.P. Caracterização do regime de fluxos e determinação da vazão ecológica por métodos hidrológicos no rio Paraná: estação de Porto São José. Relatório de Qualificação de Doutorado, Universidade Estadual de Maringá, Pós-graduação em Ecologia de Ambientes Aquáticos Continentais, Maringá. 17 p., 2008.

ROCHA, P.C. Dinâmica dos Canais no Sistema Rio-Planície Fluvial do Alto Rio Paraná, nas proximidades de Porto Rico - PR. Tese de Doutorado, Universidade Estadual de Maringá, Pósgraduação em Ecologia de Ambientes Aquáticos Continentais, Maringá. 169 p., 2002. (inédito).

ROCHA, J.A. \& SOUZA FILHO, E.E. Características geomorfológicas do canal do Rio Paraná à jusante da barragem de Porto Primavera: variação temporal e espacial dos sedimentos suspensos, de fundo e de algumas variáveis limnológicas. In: Dalva Helena de Medeiros (Org.). Relação Homem/Natureza sob a Ótica da Interdisciplinaridade. 1 ed. Campo Mourão: Editora Fecilcam, Campo Mourão, v. 1, p. 225-249, 2008.
SILVA, S.A. Características do regime hidrológico do alto rio Paraná: modificações e aspectos ambientais. Tese de Doutorado, Universidade Estadual de Maringá, Pós-graduação em Ecologia de Ambientes Aquáticos Continentais, Maringá. 142 p., 2007.

SOUZA FILHO, E.E. 1993. Aspectos da geologia e estratigrafia dos depósitos sedimentares do rio Paraná entre Porto Primavera (MS) e Guaira (PR). Tese de Doutorado, Universidade de São Paulo, Instituto de Geociências, São Paulo. 214 pp., 1993.

SOUZA FILHO, E.E. Diagnóstico do meio físico e condições emergentes da planície do rio Paraná em Porto Rico (PR). GEONOTAS, DGE/UEM, Maringá, v. 3, n.3, 12 pp., 1999.

Souza Filho, E.E. Evaluation of the Upper Paraná River discharge controlled by reservoirs. Braz. Journal. Biol. June, v. 69 n. 2, p. 707-716, 2009.

SOUZAFILHO, E.E. \& STEVAUX, J.C. A planície inundável do rio Paraná: estruturas e processos ambientais. Meio Físico-Geologia e Geomorfologia. Relatório PELD 2007. 2008 Disponível no site http://www.peld.uem.br/Relat2007/index07.htm.

SOUZA FILHO, E.E.; ROCHA, P.C.; COMUNELLO, E. \& STEVAUX, J.C. Effects of the Porto Primavera Dam on physical environment of the downstream floodplain, p. 55-74. In THOMAZ, SM., AGOSTINHO, AA. and HAHN, NS. (eds.), The Upper Paraná River and its floodplain: Physical aspects, Ecology and Conservation, Backhuys Pubblishers, Leiden, $1^{\circ}$ ed., p. 55-74, 2004.

STEVAUX, J.C. A dinâmica do fluxo e da carga de fundo no Paraná e nas desembocaduras de seus principais tributários. Modelo para gerenciamento de grandes rios aluviais impactados por barragem, mineração e hidrovia. Relatório final de projeto. FAPESP 04/14057-5. 133 p., 2007.

STEVAUX, J.C. \& TAKEDA, A.M. Geomorphological processes related to density and variety of zoobenthic community of the upper Paraná River, Brazil. Zeistshrift Fur Geomorphologie, Berlin-Stuttgart, v. 129, p. 143-158, 2002. 